\title{
The Neurodevelopmental Outcome of Severe Neonatal Hemolytic and Nonhemolytic Hyperbilirubinemia
}

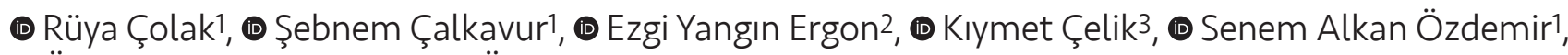 \\ [回Özgür Olukman4, 圆 Zeynep Üstünyurt5 \\ 1'zmir Dr. Behçet Uz Child Disease and Pediatric Surgery Training and Research Hospital, Neonatal İntensive Care Unit, Izmir, Turkey \\ 2 Van Training and Research Hospital, Neonatal Intensive Care Unit, Van, Turkey \\ ${ }^{3}$ Diyarbakır Gazi Yaşargil Training and Research Hospital, Neonatal İntensive Care Unit, Diyarbakır, Turkey \\ ${ }^{4}$ Çiğli Regional Education Hospital, Neonatal İntensive Care Unit, İzmir, Turkey \\ 5Zekai Tahir Burak Women's Health Training and Research Hospital, Ankara, Turkey
}

\begin{abstract}
Aim: Neonatal bilirubin-induced neurologic dysfunction can present with a wide spectrum of symptoms from mild neurologic impairment to severe acute bilirubin encephalopathy. In this study, we aimed to determine the risk factors of unconjugated hyperbilirubinemia among hospitalized infants with serum total bilirubin levels $\geq 25 \mathrm{mg} / \mathrm{dL}$ and evaluate the effects of high serum bilirubin levels due to hemolysis on neurodevelopmental outcome at postnatal between 18 and 24 months.

Materials and Methods: Thirty-six term infants were enrolled in the study. The patients were divided into two groups according to their condition of either hemolytic or nonhemolytic hyperbilirubinemia. Neurodevelopmental assessment with The Bayley scale of Infant Development-II at postnatal between 18 and 24 months was performed on all infants.

Results: Fourteen infants (38.9\%) were in the nonhemolytic group, while 22 (61.1\%) were in the hemolytic group and there was no statistically significant difference between the groups in terms of the measured mean Mental Developmental index and Psychomotor Developmental index scores. All 4 patients who underwent exchange transfusion had subgroup incompatibility and their Psychomotor Developmental index scores were significantly lower $(p<0.05)$.

Conclusion: In our study, we found that subgroup incompatibility was an important risk factor for hemolytic indirect hyperbilirubinemia and that the mean psychomotor neurodevelopmental score associated with high hyperbilirubinemia may be lower in these patients. We believe that larger case series studies are needed to discuss the relationship between subgroup nonconformity and neurodevelopmental outcomes.
\end{abstract}

Keywords: Hyperbilirubinemia, neurodevelopmental outcomes, newborn, risk factors

\section{Introduction}

Jaundice is one of the most common problems in the neonatal period. At least two-thirds of newborns have jaundice in the first week of life, and some may progress to jaundice, serious and progressive acute bilirubin encephalopathy or kernicterus causing serious mortality in the newborn $(1,2)$. Although the term Kernicterus refers to the coloration of the brain stem nucleus with bilirubin in yellow; it is used to describe the state of chronic bilirubin 
toxicity including atypical movements, hearing loss, upward gaze paralysis, and mental retardation (3). Bilirubin toxicity shows a wide spectrum in children ranging from mild and imprecise disorders to acute bilirubin encephalopathy and post-icteric auditory and neuromotor sequelae $(4,5)$. Thanks to advances in neonatal care, despite the reduction in the incidence of neurological and developmental disorders induced by bilirubin and kernicterus, severe hyperbilirubinemia-related problems still occur. Long-term neurological and developmental disorders such as cerebral palsy, sensorineural hearing loss, intellectual impairment, or growth retardation may be encountered in living infants $(6,7)$. The classical definition of cerebral palsy is a group of permanent disorders of the development of movement and posture, causing activity limitation, that is attributed to nonprogressive disturbances that occurred in the developing fetal or infant brain (8).

Our aim in this study is to determine the causes of hemolytic and nonhemolytic indirect hyperbilirubinemia in patients admitted to our hospital with indirect bilirubin level $\geq 25 \mathrm{mg} / \mathrm{dL}$; to investigate the relationship between different etiological factors and treatment modalities and neurological and developmental disorders.

\section{Materials and Methods}

This study started with a file system scan of 36 patients hospitalized due to indirect bilirubinemia over $25 \mathrm{mg} / \mathrm{dL}$ in our Neonatal Intensive Care Unit between June 2013 and January 2015. The gestational weeks (GW) of the patients, their birth weight, admission time, hemogram and biochemical levels, blood groups, $\mathrm{ABO}$ and RhD and Subgroup status, direct coombs tests, peripheral blood smear, reticulocyte, thyroid function tests (TFT) and glucose-6-phosphate dehydrogenase (G6PD) levels, bilirubin/albumin ratio and treatment modalities were recorded.

Patients were divided into two groups as hemolytic hyperbilirubinemia $(n=22)$ and nonhemolytic hyperbilirubinemia $(n=14)$ according to the status of Rh incompatibility, $\mathrm{ABO}$ incompatibility, subgroup incompatibility, and G6PD enzyme deficiency and the results were compared with each other.

The presence of $\mathrm{ABO}, \mathrm{Rh}$ or Subgroup incompatibility and G6PD deficiency and one or more signs of concomitant peripheral smear hemolysis or direct coombs test positivity or $>1 \%$ of corrected reticulocyte or a decrease in hematocrit level were considered as the presence of hemolysis.

After admission to hospital, complete blood tests were made and intensive phototherapy was applied for 4 hours while blood providence was being awaited. During the presence of proven hemolytic hyperbilirubinemia, the patients received intravenous immunoglobulin (IVIG) $1 \mathrm{~g} /$ kg for 2 hours. Intensive phototherapy continued when the patient's venous bilirubin level remained below the blood exchange transfusion limit according to the bilirubin nomograms of the American Academy of Pediatrics (APA) and when there was no evidence of neurological examination finding, blood exchange transfusion was applied to the patients who exceeded the exchange transfusion limit on the same bilirubin nomogram or had physical examination findings compatible with acute bilirubin encephalopathy such as fever, lethargy, hypo/hypertonia or high-pitched crying. Follow-up of bilirubin level at the $2^{\text {nd }}$ hour, $4^{\text {th }}$ hour, $6^{\text {th }}$ hour continued after exchange transfusion (9). All patients were contacted via their registered phone numbers whilst in the age range 18-24 months to invite them to our hospital to perform "Bayley Scales of Infant Developmental Assessment scale II" (BSID). Family consent was obtained by the same developmental pediatrician. The mental development index (MDI) and psychomotor development index (PDI) values of the patients were determined, any children who could not complete the development test were given 49 points $(10,11)$. Neurodevelopmental impairment (NDI) was defined as the presence of any one of the following: (1) moderateto-severe cerebral palsy (CP; hypotonic, spastic diplegia, hemiplegia, or quadriplegia) with functional deficits that required rehabilitative services, or (2) bilateral hearing loss (requiring amplification) and/or blindness in either eye or (3) MDI or PDI scores $<70(10,11)$.

This study was approved by the local ethics committee of Behcet Uz Children's Hospital, and informed consent was obtained from the parents before enrolment (2016/70).

\section{Statistical Analysis}

For statistical analysis, "SPSS software version 17.0" was used. While "descriptive statistics" were used for demographic data, "Mann-Whitney U test" was used to compare numerical variables between groups, and "Fischer Exact test" was used to compare inter-group ratios. The value of $p<0.05$ was considered statistically significant.

\section{Results}

File data of 22 patients (61.1\%) with hemolytic hyperbilirubinemia and 14 patients (38.9\%) with nonhemolytic hyperbilirubinemia were evaluated. There was no difference between the two groups in terms of gender, birth weight, GW, birth style (Normal vaginal delivery/ Cesarean section) or the first day of jaundice (Table I). 
When patients with hemolytic indirect hyperbilirubinemia were examined, $A B O$ incompatibility was found in 10 (45\%) of 22 patients, subgroup incompatibility in 9 (41.5\%) of them, Rh incompatibility, ABO incompatibility and G6PD association in 1 (4.5\%) of them, Rh incompatibility and subgroup incompatibility association in 1 (4.5\%) of them and $\mathrm{ABO}$ incompatibility and subgroup incompatibility association in 1 (4.5\%) of them. There were 14 patients in the nonhemolytic group and urinary tract infection in 2 of them and breastfeeding jaundice and dehydration in 12 of them were noted.

The laboratory values of the two groups were compared and while there was no difference between total serum bilirubin (TSB), sodium, albumin and bilirubin/albumin ratio at diagnosis, it was found that hemoglobin and hematocrit levels were significantly lower in the hemolysis group ( $p=0.045, p=0.048$ respectively).

When the treatments of patients with hemolytic and nonhemolytic hyperbilirubinemia were compared, there was no difference between the periods of receiving phototherapy and the length of hospitalization. In the group of hemolytic hyperbilirubinemia, IVIC and intravenous fluid intake were found to be significantly different $(p=0.003, p=0.015$ respectively). It was determined that $4(11.1 \%)$ patients who were in the hemolytic hyperbilirubinemia group were given blood exchange transfusion and all of them had subgroup incompatibility.

In the evaluation of the patients via Bayley scales of Infant Developmental Assessment scale II, there was found to be bilateral deafness in $2(6.66 \%)$ of them, cerebral palsy in $1(3.33 \%)$ of them, neurological and developmental disorders in 5 (16.6\%) of them, and there was no statistically significant difference between the groups in terms of these findings and the measured mean MDI and PDI scores (Table II). Only one patient with cerebral palsy could not perform the Bayley scale II and she was given 49 points. When subgroup analysis was performed between the groups of hemolytic hyperbilirubinemia, it was seen that the mean PDI scores were significantly lower $(p=0.04)$ (Table III).

\section{Discussion}

Indirect hyperbilirubinemia and jaundice are common clinical cases in the neonatal period. With effective phototherapy techniques, acute and chronic bilirubin

Table I. Demographic characteristics of patients

\begin{tabular}{|c|c|c|c|}
\hline Patients & Non hemolytic group $(n=14)$ & Hemolytic group $(n=22)$ & $\mathbf{p}$ \\
\hline $\begin{array}{l}\text { Gender } \\
\text { Male, n (\%) } \\
\text { Female, n (\%) }\end{array}$ & $\begin{array}{l}7(50 \%) \\
7(50 \%)\end{array}$ & $\begin{array}{l}11(50 \%) \\
11(50 \%)\end{array}$ & 1 \\
\hline Birth weight, grams, Mean ( \pm SD) & $3.171 \pm 739$ & $3.080 \pm 335$ & 0.67 \\
\hline Weight at diagnosis, gr, Mean ( \pm SD) & $2.905 \pm 678$ & $2.830 \pm 401$ & 0.67 \\
\hline Gestational week, week, Mean ( \pm SD) & $38 \pm 1$ & $38.1 \pm 1.56$ & 0.81 \\
\hline $\begin{array}{l}\text { Delivery type } \\
\text { NVD, n (\%) } \\
\text { C\&S, n (\%) }\end{array}$ & $\begin{array}{l}8(57.1 \%) \\
6(42.8 \%)\end{array}$ & $\begin{array}{l}13(59 \%) \\
9(40.9 \%)\end{array}$ & 0.9 \\
\hline Maternal age, years, Mean ( \pm SD) & $25.1 \pm 5$ & $27.8 \pm 5.6$ & 0.15 \\
\hline Brother or sister with jaundice, n (\%) & $0(0 \%)$ & $8(36.3 \%)$ & 0.013 \\
\hline Dehydration presence, $\mathrm{n}(\%)$ & $12(85.7 \%)$ & $20(90.9 \%)$ & 0.63 \\
\hline Hypernatremia, n (\%) & $4(28.5 \%)$ & 6 & 0.93 \\
\hline Urinary tract infection, $\mathbf{n}(\%)$ & $2(14.2 \%)$ & $0(0 \%)$ & 1 \\
\hline The first day of jaundice, day, Mean ( \pm SD) & $3.5 \pm 1.8$ & $3 \pm 1.6$ & 0.44 \\
\hline Bilirubin/Albumin Ratio, n (\%) & $3(21.4 \%)$ & $9(40.9 \%)$ & 0.22 \\
\hline Maximum TSB*, mg/dL, Mean ( \pm SD) & $27.2 \pm 2.42$ & $28.7 \pm 4.4$ & 0.32 \\
\hline Intravenous fluid requirement, n (\%) & $1(7.1 \%)$ & $15(68.1 \%)$ & 0.015 \\
\hline $\begin{array}{l}\text { Treatment, n (\%) } \\
\text { Phototherapy } \\
\text { Phototherapy + Exchange transfusion }\end{array}$ & $\begin{array}{l}14(100 \%) \\
0\end{array}$ & $\begin{array}{l}18(81.8 \%) \\
4(18.1 \%)\end{array}$ & 0.14 \\
\hline
\end{tabular}


encephalopathy has decreased compared to previous years. However, because it causes permanent and irreversible neurological damage, early diagnosis, accurate identification of etiological factors and rapid treatment are very important. When the etiologies of 36 patients with severe indirect hyperbilirubinemia were examined during our study, hemolytic causes were found in $61.1 \%$ of them and as expected, these patients had lower hemoglobin values and higher levels of intravenous fluid and IVIC treatment. While exchange transfusion was not performed in the patient group without hemolysis, it is notable that all 4 patients who were given exchange transfusion had subgroup incompatibility. In a study conducted by Chen et al. (12), 128 newborns admitted for hyperbilirubinemia were divided into 2 groups, namely hemolytic $(n=29)$ and nonhemolytic $(n=99)$ and they found that the blood exchange rate was higher in the hemolytic group (13.8\%). However, in this study, patients in the hemolytic group, Rh, ABO incompatibility and G6PD deficiency were included, while subgroup incompatibility was not observed. In another study conducted by Behjati et al. (13), similarly, $A B O$ incompatibility was found to be the

\begin{tabular}{|l|l|l|l|}
\hline \multicolumn{3}{|l|}{ Table II. Neurodevelopmental outcomes } \\
\hline & $\begin{array}{l}\text { Nonhemolytic } \\
\text { Group } \\
\mathbf{n = 1 4}\end{array}$ & $\begin{array}{l}\text { Hemolytic } \\
\text { Group } \\
\mathbf{n = 2 2}\end{array}$ & $\mathbf{p}$ \\
\hline Cerebral palsy, n (\%) & 0 & $1(4.5 \%)$ & 1 \\
\hline Deafness, n (\%) & 0 & $2(9 \%)$ & 0.52 \\
\hline Blindness, n (\%) & 0 & 0 & NS \\
\hline NDI, n (\%) & $2(14.2 \%)$ & $3(13.5 \%)$ & 1 \\
\hline MDI, mean \pm SD & $91.0 \pm 18.3$ & $91.0 \pm 16.0$ & 0.98 \\
\hline PDI, mean \pm SD & $89.1 \pm 17.2$ & $93.7 \pm 17.5$ & 0.47 \\
\hline $\begin{array}{l}\text { MDI: Mental developmental index, PDI: Psychomotor developmental index, } \\
\text { NDI: Neurodevelopmental impairment, SD: Standard deviation, n: Number, } \\
\text { NS: Not significant }\end{array}$ & & \\
\hline
\end{tabular}

most important cause of exchange transfusion in neonatal jaundice. In the study conducted by Annagür et al. (14), when the etiologies of 82 babies who were admitted to a Neonatal Unit due to neonatal jaundice and who received an exchange transfusion were examined, the most common causes of exchange transfusion were reported to be $A B O$ incompatibility (31\%) and Rh incompatibility and subgroup incompatibility (17\%). In another study carried out in our clinic in 2009, in the etiological examination of 107 patients, ABO incompatibility was found in 56 (24.3\%) patients, Rh incompatibility in 29 (12.6\%) patients, urinary tract infection in $14(6 \%)$ patients and subgroup incompatibility in 7 (3\%) patients (15). We think that, conversely, in our study, the reason for the occurrence of subgroup incompatibility in all of those patients who underwent an exchange transfusion was the investigation of subgroup disagreement in all patients with a high bilirubin level and that the number of patients who received an exchange transfusion was low. This result, however, is still important as it indicates that subgroups should be examined to clarify the etiology in the case of major blood group incompatibility or G6PD deficiency in patients with severe hyperbilirubinemia.

According to the effects of a neurodevelopmental evoliation of 36 patients by severe indirect hyperbilirubinemia, the rates of mean $\mathrm{MDI}$ and mean PDI were found to be similar in both groups. In the hemolysis group, one patient with cerebral palsy and hearing loss and one patient with only hearing loss were identified. Although this result did not make a statistical difference, when the patient with cerebral palsy and sensorineural hearing loss was evaluated in detail, it was found that the total bilirubin level was 43.3 $\mathrm{mg} / \mathrm{dL}$, the B/A ratio was 13.1 and there was "E" subgroup incompatibility, and it was also seen that he had spent 36 hours over the value that required phototherapy. In a study conducted by Yvonne et al. (16), cerebral palsy development

\begin{tabular}{|c|c|c|c|c|c|c|}
\hline & $\begin{array}{l}\text { Total Bilirubin Levels, } \\
\text { mg/dL, } \\
\text { Mean ( } \pm \text { SD) }\end{array}$ & $\begin{array}{l}\text { p Total Bilirubin } \\
\text { Levels }\end{array}$ & $\begin{array}{l}\text { MDI, } \\
\text { Mean, } \\
\pm \text { SD }\end{array}$ & p MDI & $\begin{array}{l}\text { PDI, Mean, } \\
\pm \text { SD }\end{array}$ & p PDI \\
\hline $\begin{array}{l}\text { ABO incompatibility } \\
(+), n=12 \\
(-), n=24\end{array}$ & $\begin{array}{l}28.9 \pm 4.3 \\
26.7 \pm 1.9\end{array}$ & 0.04 & $\begin{array}{l}91.9 \pm 17.9 \\
89.3 \pm 14.3\end{array}$ & 0.34 & $\begin{array}{l}92.6 \pm 18.7 \\
91 \pm 18.9\end{array}$ & 0.62 \\
\hline $\begin{array}{l}\text { Rh incompatibility } \\
(+), n=2 \\
(-), n=34\end{array}$ & $\begin{array}{l}26.6 \pm 1.1 \\
28.2 \pm 3.9\end{array}$ & 0.55 & $\begin{array}{l}90.6 \pm 16.7 \\
96 \pm 19.7\end{array}$ & 0.86 & $\begin{array}{l}90.6 \pm 10.6 \\
92.2 \pm 31.2\end{array}$ & 0.96 \\
\hline $\begin{array}{l}\text { Subgroup incompatibility } \\
(+), n=11 \\
(-), n=25\end{array}$ & $\begin{array}{l}31.3 \pm 5.1 \\
26.8 \pm 1.9\end{array}$ & 0.016 & $\begin{array}{l}95.6 \pm 19.3 \\
88.7 \pm 15.0\end{array}$ & 0.11 & $\begin{array}{l}86,4 \pm 16.4 \\
99.4 \pm 21.0\end{array}$ & 0.04 \\
\hline
\end{tabular}


was found in $7(0.4 \%)$ of the 1,833 patients who had an exchange transfusion and $86(0.1 \%)$ of the 104,716 patients who did not have exchange transfussion. In those patients who had exchange transfusion, cerebral palsy induced by kernicterus was found in only 3 patients and the incidence was found to be $0.57 \%$ for live births. It was found that there were at least 2 more risk factors for neurotoxicity in the 3 infants who had exchange transfusion and that these risk factors were seen in infants who were premature, who had G6PD deficiency and hypoxic-ischemic encephalopathy; and consequently, it was reported that cerebral palsy induced by kernicterus was seen in infants having a risk factor for 2 or more neurotoxicity and whose TSB level was above the $5 \mathrm{mg} / \mathrm{dL}$ limit, and the risk of cerebral palsy development at low TSB levels was minimal.

The other patient with hearing loss was $35 \mathrm{Gw}$ and had $A B O$ incompatibility, their TSB level was $25 \mathrm{mg} /$ $\mathrm{dL}, 8 \mathrm{mg} / \mathrm{dL}$ more than the exchange transfusion limit and that they stayed 3 hours longer over the exchange transfusion limit, and these were determined as the risk factors for sensorineural hearing loss. In a study in which Wickremasinghe et al. (17) investigated sensorineural hearing loss in patients who had undergone exchange transfusion, bilirubin levels which were above $10 \mathrm{mg} / \mathrm{dL}$ more than exchange transfusion limit were associated with sensorineural hearing loss, and a relationship between a lower risk of developing sensorineural hearing loss and lower TSB levels was found.

The mean PDI values of patients with subgroup incompatibility were found to be lower when the mean MDI and mean PDI scores of patients with and without subgroup incompatibility were evaluated. Neurodevelopmental investigations should be made in a large series of patients with subgroup incompatibility, and cognitive development should be closely monitored in this group of patients with excessive hemolysis. The limitation of our study is that the number of patients admitted during the study period was low.

\section{Conclusion}

In conclusion, our study shows that there is no difference between the neurodevelopmental outcomes of hemolytic and nonhemolytic indirect hyperbilirubinemia. Subgroup incompatibility is one of the important risk factors in the hemolytic hyperbilirubinemia group, and that the subgroup level of patients with high bilirubin levels should be examined, and that there are similar results in the neurodevelopmental evaluation of the two groups, except for cerebral palsy and deafness, and that mean PDI values could be low in subgroup incompatibility. However, for this assessment to give better results, it is necessary to conduct studies in multi-centered research with a large series of patients.

\section{Ethics}

Ethics Committee Approval: This study was approved by the local ethics committee of Behcet Uz Children's Hospital, (2016/70).

Informed Consent: Informed consent was obtained from the parents.

Peer-review: Externally and internally peer-reviewed.

\section{Authorship Contributions}

Design: R.Ç., Ş.Ç., Data Collection or Processing: E.Y.E., K.Ç., S.A.Ö., Analysis or Interpretation: Ö.O., Z.Ü., Literature Search: Ö.O., Z.Ü., Writing: R.Ç.

Conflict of Interest: No conflict of interest was declared by the authors.

Financial Disclosure: The authors declared that this study received no financial support.

\section{References}

1. Schwartz HP, Haberman BE, Ruddy RM. Hyperbilirubinemia: current guidelines and emerging therapies. Pediatr Emerg Care 2011;27:884-9.

2. Hameed NN, R Vilms, and VK Bhutani. Severe neonatal hyperbilirubinemia and adverse short-term consequences in Baghdad, Iraq. Neonatology 2011;100:57-63.

3. Kaplan M, Bromiker R, Hammerman C. Severe neonatal hyperbilirubinemia and kernicterus: are these still problems in the third millennium? Neonatology 2011;100:354-62.

4. Johnson L, Brown A, Bhutani V. BIND-A clinical score for bilirubin induced neurologic dysfunction in newborns. Pediatrics 1999;104:746-7.

5. Shapiro SM. Definition of the clinical spectrum of kernicterus and bilirubin-induced neurologic dysfunction (BIND). J Perinatol 2005;25:54.

6. Mwaniki MK, Atieno M, Lawn JE, Newton CR. Long-term neurodevelopmental outcomes after intrauterine and neonatal insults: a systematic review. Lancet 2012;379:445-52.

7. Maulik PK, Darmstadt GL. Childhood disability in low-and middle-income countries: overview of screening, prevention, services, legislation, and epidemiology. Pediatrics 2007;120:1-55.

8. Rosenbaum $P$, Paneth $N$, Leviton A, et al. A report: the definition and classification of cerebral palsy April 2006. DMCN 2007;109:8-14.

9. American Academy of Pediatrics Subcommittee on Hyperbilirubinemia. Management of hyperbilirubinemia in the newborn infant 35 or more weeks of gestation. Pediatrics 2004;114:297.

10. Bayley N. Bayley scales of infant development: Manual. 1993: PsychologicalCorporation. 
11. Oncel MY, Eras Z, Uras N, Canpolat FE, Erdeve O, Oguz SS. Neurodevelopmental outcomes of preterm infants treated with oral paracetamol versus ibuprofen for patent ductus arteriosus. Am J Perinatol 2017;34:1185-9.

12. Chen WX, VC Wong, KY Wong, Neurodevelopmental outcome of severe neonatal hemolytic hyperbilirubinemia. I Child Neurol 2006;21:474-9.

13. Behjati SH, Sagheb S, Aryasepehr S, Yaghmai B. Adverse events associated with neonatal exchange transfusion for hyperbilirubinemia. Indian J Pediatr 2009;76:83-5.

14. Annagür $\mathrm{A}$, Altunhan $\mathrm{H}$, Konak $\mathrm{M}$, Koç $\mathrm{H}$, Örs R. Role of subgroup incompatibility in newborn jaundice requiring exchange transfusion. Electron / Gen Med 2014;11.
15. Orgun A, Çalkavur \$̧, Özgür Olukman LT, et al. Role of minor erythrocyte antigens on alloimmunızation in neonatal indirect hyperbilirubinemia background. Turk Pediatri Ars 2013;48:23-30.

16. Yvonne Wu , Kuzniewicz MW, Wickremasinghe AC, et al. Risk for cerebral palsy in infants with total serum bilirubin levels at or above the exchange transfusion threshold: a population-based study. JAMA Pediatr 2015;169:239-46.

17. Wickremasinghe AC, Risley RJ, Kuzniewicz MW, et al. Risk of sensorineural hearing loss and bilirubin exchange transfusion thresholds. Pediatrics 2015;136:505-12. 